\title{
Nitric Oxide and Prostaglandins - Important Players in Endothelin-1 Induced Myocardial Distensibility
}

\author{
C. BRÁS-SILVA, D. MONTEIRO-SOUSA, A. J. DUARTE, M. GUERRA, \\ A. P. FONTES-SOUSA, C. MOURA, J. C. AREIAS, A. F. LEITE-MOREIRA \\ Department of Physiology, Faculty of Medicine, University of Porto, Portugal
}

Received November 2, 2006

Accepted March 26, 2007

On-line available May 30, 2007

\section{Summary}

This study investigated whether endothelin (ET)-1-induced increase in myocardial distensibility is preserved in heart failure (HF) and whether it is modulated by nitric oxide (NO) and prostaglandins. New Zealand white rabbits were treated with doxorubicin $(1 \mathrm{mg} / \mathrm{kg}$, intravenously twice a week for 8 weeks, DOX-HF group) or saline (control group). Effects of ET-1 (0.1, 1 , $10 \mathrm{nM}$ ) were tested in papillary muscles from the DOX-HF group and a control group in the presence of: i) intact endocardial endothelium (EE); ii) damaged $\mathrm{EE}$; iii) $\mathrm{N}^{\mathrm{G}}$-nitro-L-arginine (L-NNA; NO synthase inhibitor), and iv) indomethacin (INDO; cyclooxygenase inhibitor). In the presence of an intact EE, ET-1 promoted concentration-dependent positive inotropic and lusitropic effects that were maintained after damaging the $E E$, in the presence of L-NNA or INDO and in the DOX-HF Group. ET-1 reduced resting tension at the end of the isometric twitch (increased diastolic distensibility) by $3.2 \pm 1.3 \%, 6.0 \pm 1.6 \%$ and $8.8 \pm 2.7 \%$ (at $0.1,1$ and $10 \mathrm{nM}$, respectively), in muscles with intact $\mathrm{EE}$, effect that was completely abolished after damaging $\mathrm{EE}$, in the presence of L-NNA or INDO or in the DOX-HF Group. This study demonstrated that the increase in myocardial distensibility induced by ET- 1 is absent in HF and is dependent of NO and prostaglandin release.

\section{Key words}

Endothelin • Endothelium • Heart failure • Diastolic properties • Myocardial distensibility

\section{Corresponding author}

A. F. Leite-Moreira, Department of Physiology, Faculty of Medicine, Alameda Professor Hernâni Monteiro, 4200-319 Porto, Portugal. Fax: +351 22 551.36.46. E-mail: amoreira@med.up.pt

\section{Introduction}

The discovery of endothelin (ET)-1, one of the most potent endogenous vasoconstrictor peptides, by Yanagisawa et al. (1988) represented a landmark in the field of cardiovascular research. Since its discovery, a great deal of effort has been exerted in gaining a better understanding of the key roles (developmental, physiological, and pathological) played by this peptide, particularly with regard to the cardiovascular system, where the components of the endothelin system are widely expressed, namely in vascular and endocardial endothelium, smooth muscle cells and cardiomyocytes (Brunner et al. 2006). ET-1 acts in two main subtypes of G-protein coupled receptors $\left(\mathrm{ET}_{\mathrm{A}}\right.$ and $\left.\mathrm{ET}_{\mathrm{B}}\right)$ and has mainly local autocrine and paracrine actions, since it is released abluminally and has a short half-life. In heart failure (HF), the plasma, salivary and tissue levels of ET-1 are increased and are positively related to the stage of the disease and negatively to its prognosis (Attina et al. 2005). $\mathrm{ET}_{\mathrm{A}}$ receptors mediate vasoconstriction, mitogenesis and positive inotropism. $\mathrm{ET}_{\mathrm{B}}$ receptor activation promotes mainly vasodilatation and has growth inhibitory effects associated with apoptosis. These receptors also mediate the pulmonary clearance of circulating ET-1 and the reuptake of ET-1 by endothelial cells. In the heart (Leite-Moreira and Bras-Silva 2004) and in the vasculature (Endoh et al. 1998), it is possible to further subclassify the $\mathrm{ET}_{\mathrm{B}}$ receptors into $\mathrm{ET}_{\mathrm{B} 1}$ receptors, located on the vascular and endocardial endothelium and responsible for vasodilatation and negative inotropism, and $\mathrm{ET}_{\mathrm{B} 2}$ receptors, located on

PHYSIOLOGICAL RESEARCH • ISSN 0862-8408 (print) • ISSN 1802-9973 (online)

(c) 2008 Institute of Physiology v.v.i., Academy of Sciences of the Czech Republic, Prague, Czech Republic

Fax+420 241062 164, e-mail: physres@biomed.cas.cz, www.biomed.cas.cz/physiolres 
vascular muscular and myocardial cells and responsible for vasoconstriction and positive inotropism, respectively.

Unlike the well-known role of chronically elevated ET-1 levels in progression of cardiac fibrosis and ventricular remodeling, the acute diastolic effects of ET-1 in the failing myocardium remain less explored. We have previously reported, in healthy animals that ET-1 acutely decreases myocardial stiffness under the conditions of cardiac overload (Leite-Moreira et al. 2003). Although mediated by $\mathrm{ET}_{\mathrm{A}}$ receptor stimulation (Leite-Moreira et al. 2003), this effect requires an intact endocardial endothelium (EE) and active endothelial $\mathrm{ET}_{\mathrm{B} 1}$ receptors (Bras-Silva and Leite-Moreira 2006). This is in agreement with the growing experimental evidence for a paracrine regulation of cardiac systolic and diastolic performance by endocardial endothelial cells that is analogous to vascular endothelial control of vascular tone (Brutsaert 2003). Until recently, a major limitation for the evaluation of EE dysfunction was the non-existence of a functional marker, such as acetylcholine for the vascular endothelium. We have recently gathered evidence that the response to selective $\mathrm{ET}_{\mathrm{B}}$ receptor stimulation might be used as such a marker. Using this approach we documented endocardial endothelial dysfunction in an experimental model of HF, the so-called doxorubicininduced HF (Bras-Silva et al. 2006).

In this context, the present study was conducted in order to investigate whether the diastolic effects of ET1 were preserved in HF, and whether they are dependent on two of the most important endothelial mediators, nitric oxide and prostaglandins.

\section{Methods}

The investigation conforms to the Guide for the Care and Use of Laboratory Animals published by the US National Institutes of Health (NIH Publication $N^{\circ} 85-23$, Revised 1996). The study was performed on NewZealand White rabbits (Oryctolagus cuniculus; $\mathrm{n}=37$; 1.8-3.0 kg).

\section{Heart failure model}

A well documented regimen was used for the induction of HF due to doxorubicin toxicity (DOX-HF) (Arnolda et al. 1985). Adult male New Zealand White rabbits received doxorubicin (DOX) via a marginal ear vein by bolus injection $(1 \mathrm{mg} / \mathrm{kg}$ ) twice weekly for 8 weeks $(n=16)$ followed by a washout period of 1 week.
Control rabbits $(\mathrm{n}=21)$ received the vehicle $(0.9 \%$ saline $)$ in equivolumetric doses over the same period. Echocardiographic evaluation of all the animals was used to monitor left ventricular dilatation and dysfunction during the development of HF. In two subgroups of control and DOX-HF hemodynamic evaluation was also performed. The experimental protocols were carried out in an isolated papillary muscle model.

\section{Echocardiographic evaluation}

All animals were evaluated by echocardiography at the beginning and every two weeks during the administration of DOX or vehicle. Echocardiographic examination was performed as previously described (Fontes-Sousa et al. 2006). Briefly, the rabbits were lightly anesthetized with an intramuscular combination of ketamine hydrochloride $(2 \mathrm{mg} / \mathrm{kg}$ ) and medetomidine hydrochloride $(0.15 \mathrm{mg} / \mathrm{kg})$, being allowed to breath spontaneously. The animals were placed prone on a table with an area removed so that the ultrasound probe could be brought from below and placed on a shaved area of the anterior chest wall. The echocardiograms were obtained using a $7.5 \mathrm{MHz}$ transducer (Vivid 3 General Electrics echocardiograph, Portugal) and the examination was performed from the right parasternal short-axis view. Two-dimensional guided M-mode tracings were made just below the mitral valve at the level of the papillary muscles for measurements of the left ventricular internal diameter and the left ventricular wall was free in diastole and systole. Three representative cycles were measured and averaged for each rabbit at each time point. Analyzed parameters were: heart rate, anterior and posterior enddiastolic and end-systolic wall thickness, left ventricular end-systolic and end-diastolic diameters (ESD and EDD, respectively), fractional shortening (FS) [FS=(EDDESD)/EDD].

\section{Hemodynamic assessment}

The instrumentation of the animals for hemodynamic studies was performed one week after the last administration of the vehicle $(n=6)$ or DOX $(n=9)$, respectively, as previously described (Leite-Moreira et al. 1999, Leite-Moreira and Correia-Pinto 2001). In summary, animals were premedicated with ketamine hydrochloride $(50 \quad \mathrm{mg} / \mathrm{kg} \quad$ i.m. $)$ and xylazine hydrochloride (5 mg/kg i.m.). An auricular vein was cannulated, and a prewarmed solution containing $20 \mathrm{mM}$ $\mathrm{KCl}$ and $40 \mathrm{mM} \mathrm{NaHCO}_{3}$ in $500 \mathrm{ml}$ of $0.9 \% \mathrm{NaCl}$ was administered to compensate for perioperative fluid losses. 
A tracheostomy was performed, and mechanical ventilation was initiated (Harvard Small Animal Ventilator, model 683), delivering oxygen-enriched air. Respiratory rate and tidal volume were adjusted to keep arterial blood gases and $\mathrm{pH}$ within physiological limits. Anesthesia was maintained with ketamine hydrochloride (33 $\mathrm{ml} / \mathrm{kg} / \mathrm{h}$ i.m.) and pentobarbital sodium $(12.5 \mathrm{mg} / \mathrm{kg}$ i.v. before opening the chest, and then $2.5 \mathrm{mg} / \mathrm{kg} i . v$. as needed). A 20-gauge catheter was inserted into the right femoral artery and connected to a pressure transducer to monitor heart rate and arterial pressure, and to obtain samples for blood gas analysis. The heart was exposed by a median sternotomy, and the pericardium was widely opened. Transient aortic constrictions were performed by abruptly occluding the aorta with a silk suture placed around the ascending aorta during the diastole separating two heartbeats. This was achieved by pushing a plastic tube against the aorta with one hand while pulling the silk suture with the other hand. Aortic constriction was quickly released to avoid neurohumoral reflex changes in cardiac function (Leite-Moreira et al. 1999, LeiteMoreira and Correia-Pinto 2001, Correia-Pinto et al. 2006). Peak systolic pressure of isovolumetric heartbeats, which can be obtained with aortic occlusions, is a sensitive index of left ventricular contractility. A 3-F high-fidelity micro-manometer (SPR-524, Millar Instruments, Houston, TX, U.S.A.) was inserted through an apical puncture wound into the left ventricular (LV) cavity, positioned at the midventricular level, and secured in place with a purse-string suture to measure LV pressure. The manometer was calibrated against a mercury column and zeroed after stabilization for $30 \mathrm{~min}$ in a water bath at body temperature. A limb electrocardiogram (DII) was recorded throughout.

After complete instrumentation, we allowed the animal preparation to stabilize for $30 \mathrm{~min}$ before the beginning of the experimental protocol. Recordings were made with respiration suspended at the end of expiration.

Parameters were converted on-line to digital data with a sampling frequency of $500 \mathrm{~Hz}$. LV pressures were measured at end diastole and peak systole. Peak rates of LV pressure rise $\left(\mathrm{dP} / \mathrm{dt}_{\max }\right)$ and pressure fall $\left(\mathrm{dP} / \mathrm{dt}_{\min }\right)$ were also measured. The relaxation rate was estimated with the time constant $\tau$ by fitting the isovolumetric pressure fall to a monoexponential function.

Anesthetics ketamine hydrochloride (Imalgene 1000®), medetomidine hydrochloride (Domitor ${ }^{\circledR}$ ) and xylazine hydrochloride (Rompum ${ }^{\circledR}$ ) were obtained from Merial Portuguesa - Saúde Animal, Pfizer Saúde Animal, and Bayer, Portugal, respectively.

\section{Papillary muscle studies}

The study was performed in isolated right papillary muscles from the control $(n=41)$ and DOX-HF $(n=15)$ groups one week after the last drug or saline administration. Rabbits were anesthetized with intravenous pentobarbital sodium $(25 \mathrm{mg} / \mathrm{kg})$. A left thoracotomy was performed and beating hearts were quickly excised and immersed in modified Krebs-Ringer (KR) solution (composition in mmol/l: $\mathrm{NaCl} 98 ; \mathrm{KCl} 4.7$; $\mathrm{MgSO}_{4}$ 2.4; $\mathrm{KH}_{2} \mathrm{PO}_{4} 1.2 ;$ glucose $4.5 ; \mathrm{CaCl}_{2}$ 1.8; $\mathrm{NaHCO}_{3} 17 ; \mathrm{C}_{3} \mathrm{H}_{3} \mathrm{NaO}_{3} 15 ; \mathrm{CH}_{3} \mathrm{COONa}$ 5; atenolol 0.02) at $35{ }^{\circ} \mathrm{C}$ with cardioplegic 2,3-butanedione monoxime (BDM; $3 \%$ ) and $5 \%$ of newborn calf serum and gassed with $95 \% \mathrm{O}_{2} / 5 \% \mathrm{CO}_{2}$, to obtain $\mathrm{pH}$ between 7.38-7.42.

After dissection, papillary muscles (length: $4.2 \pm 0.3 \mathrm{~mm}$; weight: $2.9 \pm 0.3 \mathrm{mg}$; preload: $4.3 \pm 0.3 \mathrm{mN}$ ) were mounted vertically in a $10 \mathrm{ml}$ plexi glass organ bath containing the above-described KR solution and attached to an electromagnetic length-tension transducer (University of Antwerp, Belgium). Preload was estimated according to muscle dimensions and the electrical stimulus $(0.6 \mathrm{~Hz})$ was set at $10 \%$ above threshold. Twenty minutes later, bathing solutions were replaced by corresponding KR solutions without BDM. During the next two hours, muscles were stabilized. Bathing solutions were then replaced by corresponding KR solutions without calf serum and maximum physiological length $\left(\mathrm{L}_{\max }\right)$ was calculated. Protocols were initiated after obtaining two similar isotonic and isometric control twitches separated by a 10 min interval.

\section{Experimental protocols}

In a set of papillary muscles from control $(n=8)$ and DOX-HF $(n=7)$ groups, isometric contractilityfrequency relationships were obtained by plotting maximum velocity of tension rise against frequency of contraction. In summary, after an initial period of contraction at $0.6 \mathrm{~Hz}$, the frequency of stimulation was stepped up at 3-min intervals to $1 \mathrm{~Hz}, 2 \mathrm{~Hz}, 3 \mathrm{~Hz}$ and $4 \mathrm{~Hz}$.

Myocardial effects of increasing concentrations of ET-1 (0.1, 1, and $10 \mathrm{nM})$ were studied in rabbit papillary muscles from: i) Control Group with intact endocardial endothelium (EE) $(n=9)$; ii) Control Group with damaged $\operatorname{EE~}(n=9)$; iii) Control Group in the presence $\mathrm{N}^{\mathrm{G}}$-nitro-L-arginine (L-NNA; nitric oxide synthase inhibitor, $1 \mu \mathrm{M}, \mathrm{n}=8$ ); iv) Control Group in the presence of indomethacin (INDO; cyclooxygenase 
inhibitor, $1 \mu \mathrm{M}, \mathrm{n}=7$ ) and (v) DOX-HF Group ( $\mathrm{n}=8$ ).

The concentrations of ET-1 were selected on the basis of several studies showing that its physiological effects on contraction and distensibility of myocardial tissue preparations or whole heart preparations are exerted by concentrations in the nanomolar range (Shah et al. 1989, Firth et al. 1990, Leite-Moreira et al. 2003, Bras-Silva and Leite-Moreira 2006).

EE was damaged by briefly ( $1 \mathrm{~s})$ exposing the isolated papillary muscle to a weak solution $(0.5 \%)$ of the detergent Triton X-100 (Brutsaert et al. 1988, LeiteMoreira and Bras-Silva 2004).

Chemicals were obtained from Sigma Chemical Company (St. Louis, MO).

\section{Data analysis}

Isotonic and isometric twitches were recorded and analyzed. Selected parameters include: resting tension (RT) at the beginning $\left(\mathrm{RT}_{\text {beg }}, \mathrm{mN} / \mathrm{mm}^{2}\right)$ and at the end $\left(\mathrm{RT}_{\text {end }}, \mathrm{mN} / \mathrm{mm}^{2}\right)$ of the twitch; active tension (AT, $\left.\mathrm{mN} / \mathrm{mm}^{2}\right)$; maximum velocity of tension rise $\left(\mathrm{dT} / \mathrm{dt}_{\max }\right.$, $\mathrm{mN} / \mathrm{mm}^{2} / \mathrm{s}$ ); maximum velocity of tension decline $\left(\mathrm{dT} / \mathrm{dt}_{\min }, \mathrm{mN} / \mathrm{mm}^{2} / \mathrm{s}\right)$; peak isotonic shortening (PS, $\left.\% \mathrm{~L}_{\max }\right)$; maximum velocity of shortening ( $\mathrm{dL} / \mathrm{dt}_{\max }$, $\left.\mathrm{L}_{\max } / \mathrm{s}\right)$, maximum velocity of lengthening $\left(\mathrm{dL} / \mathrm{dt}_{\min }\right.$, $\mathrm{L}_{\max } / \mathrm{s}$ ) and time to half relaxation (tHR, $\mathrm{ms}$ ).

When a pharmacological inhibitor (L-NNA or INDO) was used, the term baseline refers to the condition in the presence of those inhibitors before the addition of ET-1.

In the various protocols, results are given as the percentage change from baseline. For the parameters that are expressed as negative values (e.g. $\mathrm{dT} / \mathrm{dt}_{\min }$ ) such percentage change refers to the absolute values.

\section{Statistical methods}

Values are means \pm S.E.M. Baseline performance of papillary muscles from control and DOXtreated rabbits were compared with an unpaired t-test. Effects of increasing concentrations of ET-1 and of increasing stimulation frequencies on papillary muscles from control and DOX-treated rabbits were analyzed with a repeated-measures two-way ANOVA. Echocardiographic data of DOX-treated animals at the beginning and at the end of the study were compared with a paired $t$ test. Hemodynamic measurements at baseline and after treatment with DOX or saline were analyzed with a repeated-measures two-way ANOVA. When significant differences were detected, the Student-Newman-Keuls test was selected to perform multiple comparisons. Differences were considered to be significant when $\mathrm{P}<0.05$.

\section{Results}

\section{Cardiac hemodynamics and echocardiography}

The hemodynamic features of the experimental groups are summarized in Table 1. In comparison with the control group, the DOX-HF group presented a lower systolic pressure, $\mathrm{dP} / \mathrm{dt}_{\max }$ and peak systolic isovolumetric pressure. The left ventricular filling pressure, as estimated by left ventricular end-diastolic pressure, was increased in DOX-HF, whereas the $\mathrm{dP} / \mathrm{dt}_{\min }$ was decreased and the relaxation time constant $\tau$ was increased in the DOX-HF (Table 1).

Table 1. Hemodynamic data of rabbits from the control and doxorubicin-induced heart failure (DOX-HF) groups.

\begin{tabular}{lcc}
\hline & $\begin{array}{c}\text { Control } \\
\text { group } \\
(\mathbf{n}=\mathbf{6})\end{array}$ & $\begin{array}{c}\text { DOX-HF group } \\
(\mathbf{n}=\mathbf{9})\end{array}$ \\
\hline$L V S P, m m H g$ & $64.8 \pm 4.7$ & $47.7 \pm 9.7^{*}$ \\
$L V E D P, m m H g$ & $1.2 \pm 0.3$ & $2.28 \pm 0.34^{*}$ \\
$d P / d t_{\max }, \mathrm{mmHg} / \mathrm{s}$ & $3026.0 \pm 244.0$ & $1274 \pm 266.0^{*}$ \\
$d P / d t_{\min }, \mathrm{mmHg} / \mathrm{s}$ & $-2004.0 \pm 378.0$ & $-992.0 \pm 171.0^{*}$ \\
$L V P_{I S O}, \mathrm{mmHg}$ & $148.9 \pm 9.2$ & $84.6 \pm 13.5^{*}$ \\
$\tau, \mathrm{ms}$ & $36.6 \pm 7.7$ & $68.9 \pm 7.1^{*}$ \\
\hline
\end{tabular}

Values are mean \pm S.E.M. LVEDP and LVSP, left ventricular enddiastolic and systolic pressures, respectively; $\mathrm{dP} / \mathrm{dt}_{\max }$ and $\mathrm{dP} / \mathrm{dt}_{\text {min, }}$ peak rates of ventricular pressure rise and fall, respectively; $\mathrm{LVP}_{\mathrm{ISO}}$, peak systolic isovolumetric pressure; $\tau$, time constant of isovolumetric relaxation. $* P<0.05 \mathrm{vs}$. Control group.

Furthermore, the echocardiographic evaluation in the DOX-HF group demonstrated a progressive increase of the end-diastolic (from $14.2 \pm 0.3$ to $15.2 \pm 0.3$ $\mathrm{mm}$ ) and end-systolic (from $9.9 \pm 0.2$ to $11.1 \pm 0.3 \mathrm{~mm}$ ) short-axis diameters and a reduction in fractional shortening (from $32 \pm 1$ to $26 \pm 1 \%$ ) and ejection fraction (from $64 \pm 1$ to $56 \pm 2 \%$ ) of the left ventricle. This was consistent with the presence of dilated cardiomyopathy and HF. None of the other parameters measured changed significantly after doxorubicin treatment, namely heart rate (158 \pm 6 vs. $144 \pm 7 \mathrm{bpm})$, left wall thickness in diastole $(2.26 \pm 0.07$ vs. $2.20 \pm 0.05 \mathrm{~mm})$ and left wall thickness in systole $(3.40 \pm 0.13$ vs. $3.42 \pm 0.11 \mathrm{~mm})$. 
Table 2. Mean values of the baseline contractile parameters in papillary muscle from the control and doxorubicin-induced heart failure (DOX-HF) groups.

\begin{tabular}{cccc}
\hline \multirow{2}{*}{$\begin{array}{c}\text { Contractile } \\
\text { parameter }\end{array}$} & $\begin{array}{c}\text { With EE } \\
(\mathrm{n}=32)\end{array}$ & $\begin{array}{c}\text { Without EE } \\
(\mathrm{n}=9)\end{array}$ & $\begin{array}{c}\text { DOX-HF } \\
\text { group } \\
(\mathrm{n}=15)\end{array}$ \\
\hline $\begin{array}{c}A T \\
\left(\mathrm{mN} / \mathrm{mm}^{2}\right)\end{array}$ & $23.3 \pm 2.7$ & $17.4 \pm 1.9^{*}$ & $26.3 \pm 4.3$ \\
$d T / d t_{\max }$ & $163.5 \pm 17.1$ & $112.5 \pm 11.6^{*}$ & $164.5 \pm 21.3$ \\
$\left(\mathrm{mN} / \mathrm{mm}^{2} / \mathrm{s}\right)$ & & & \\
$d T / d t_{\min }$ & $-133.1 \pm 15.3$ & $-95.2 \pm 9.6^{*}$ & $-137.8 \pm 22.2$ \\
$\left(\mathrm{mN} / \mathrm{mm}^{2} / \mathrm{s}\right)$ & & & \\
$P S$ & $12.0 \pm 0.1$ & $9.0 \pm 0.1^{*}$ & $11.0 \pm 0.1$ \\
$\left(\%\right.$ of $\left.L_{\max }\right)$ & & & \\
$d L / d t_{\max }$ & $0.89 \pm 0.1$ & $0.61 \pm 0.06^{*}$ & $0.71 \pm 0.05$ \\
$\left(L_{\max } / s\right)$ & & & $-2.43 \pm 0.2$ \\
$d L / d t_{\min }$ & $-3.20 \pm 0.40$ & $-2.01 \pm 0.2^{*}$ & \\
$\left(L_{\max } / s\right)$ & & & \\
\hline
\end{tabular}

Values are means \pm S.E.M. EE, endocardial endothelium; AT, active tension; $\mathrm{dT} / \mathrm{dt}_{\max }$ maximum velocity of tension rise; $\mathrm{dT} / \mathrm{dt}_{\min }$, maximum velocity of tension decline; PS, peak isotonic shortening; $\mathrm{dL} / \mathrm{dt}_{\max }$, maximum velocity of shortening; $\mathrm{dL} / \mathrm{dt}_{\min }$, maximum velocity of lengthening. ${ }^{*} \mathrm{P}<0.05$ vs. control group with intact $\mathrm{EE}$.

\section{Papillary muscle studies}

Mean values of the baseline contractile parameters in papillary muscles from the control group with intact EE $(n=32)$ and from the DOX-HF group $(n=15)$ are shown in Table 2. Removal of the EE $(n=9)$ resulted in a negative inotropic effect. Although baseline performance of rabbit papillary muscles was similar in the control group with intact EE and in the DOX-HF group, the contractility of papillary muscles from the control group did not significantly decline with increasing stimulation frequency, between $1 \mathrm{~Hz}$ and $4 \mathrm{~Hz}$, while the papillary muscles from the DOX-HF rabbits showed a significant decrease in contractility over the same range of stimulation frequencies, indicating contractile dysfunction and reduced contractile reserve (Fig. 1). In the presence of an intact EE, ET-1 promoted concentration-dependent positive inotropic and lusitropic effects: AT increased by $15.3 \pm 5.4 \%, 47.2 \pm 9.8 \%$ and $88.6 \pm 18.3 \%$; dT/dt $\max , 15.4 \pm 5.9 \%, 47.1 \pm 12.3 \%$ and $103.7 \pm 21.5 \%$; and $\mathrm{dT} / \mathrm{dt}_{\min }, 13.3 \pm 4.9 \%, 42.4 \pm 6.8 \%$ and $85.6 \pm 16.9 \%$ (at $0.1,1$ and $10 \mathrm{nM}$, respectively). These effects were maintained after damaging the $\mathrm{EE}$, in the presence of L-NNA or INDO and in the DOX-HF Group (Fig. 2).

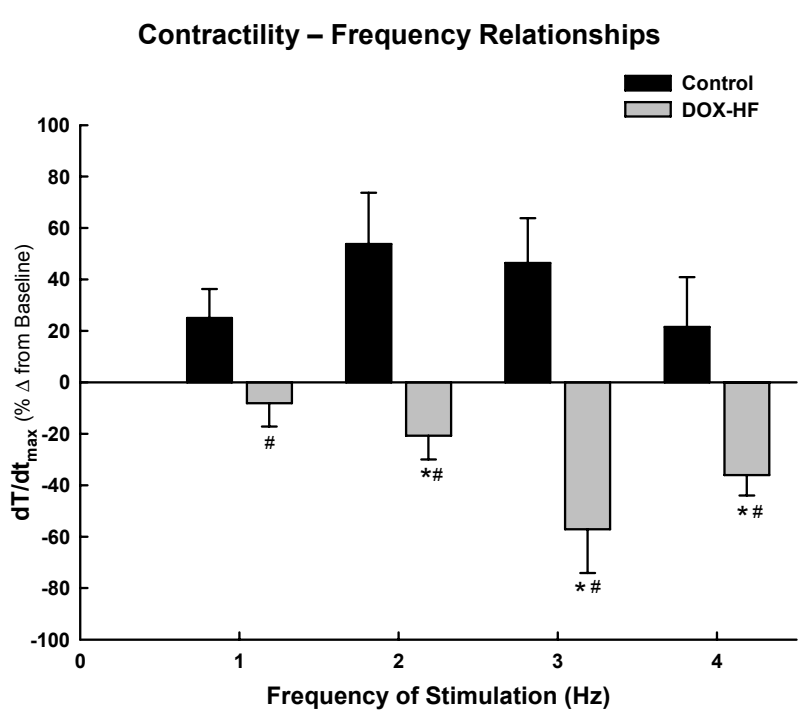

Fig. 1. Contractile response of rabbit papillary muscles from the control group $(n=8)$ and from the doxorubicin-induced heart failure (DOX-HF) group $(n=7)$ to steady increases in stimulation frequency. Contractility-frequency relationships were then obtained by plotting maximum velocity of tension rise against frequency of contraction. Control muscles showed a steady increase in contractility between $1 \mathrm{~Hz}$ and $4 \mathrm{~Hz}$, whereas in the DOX-HF group, muscles responded in the opposite way. $\mathrm{P}<0.05$ : *, vs. baseline; \#, vs. control.

Concerning the effects of ET-1 on myocardial distensibility, we found that RT significantly decreased after an isometric twitch in the presence of ET-1. Such a decrease was not significant at baseline and became progressively larger with increasing doses of ET-1 in muscles with intact EE. In fact, compared with its value at the beginning of the twitch $\left(\mathrm{RT}_{\text {beg }}\right), \mathrm{RT}$ at the end of an isometric twitch $\left(\mathrm{RT}_{\text {end }}\right)$ decreased 3.2 $\pm 1.3,6.0 \pm 1.6$ and $8.8 \pm 2.7 \%$ in the presence of $0.1,1$ and $10 \mathrm{nM}$ of ET-1, respectively (Fig. 3). Such a decrease in RT reflects an increase in myocardial distensibility, because restoring the value of RT to its initial value results in an increase in the resting length of the muscle. However, no significant differences between $\mathrm{RT}_{\text {end }}$ and $\mathrm{RT}_{\text {beg }}$ were found, when ET-1 was given after damaging the EE or in papillary muscles from the DOX-HF group. Similarly, ET-1 did not significantly alter myocardial distensibility after blocking release of NO or prostaglandins by L-NNA or INDO, respectively.

\section{Discussion}

The present study showed that the increase in myocardial distensibility induced by ET-1 is absent in DOX-HF and is dependent on NO and prostaglandin release.

The progression of cardiac dysfunction was 

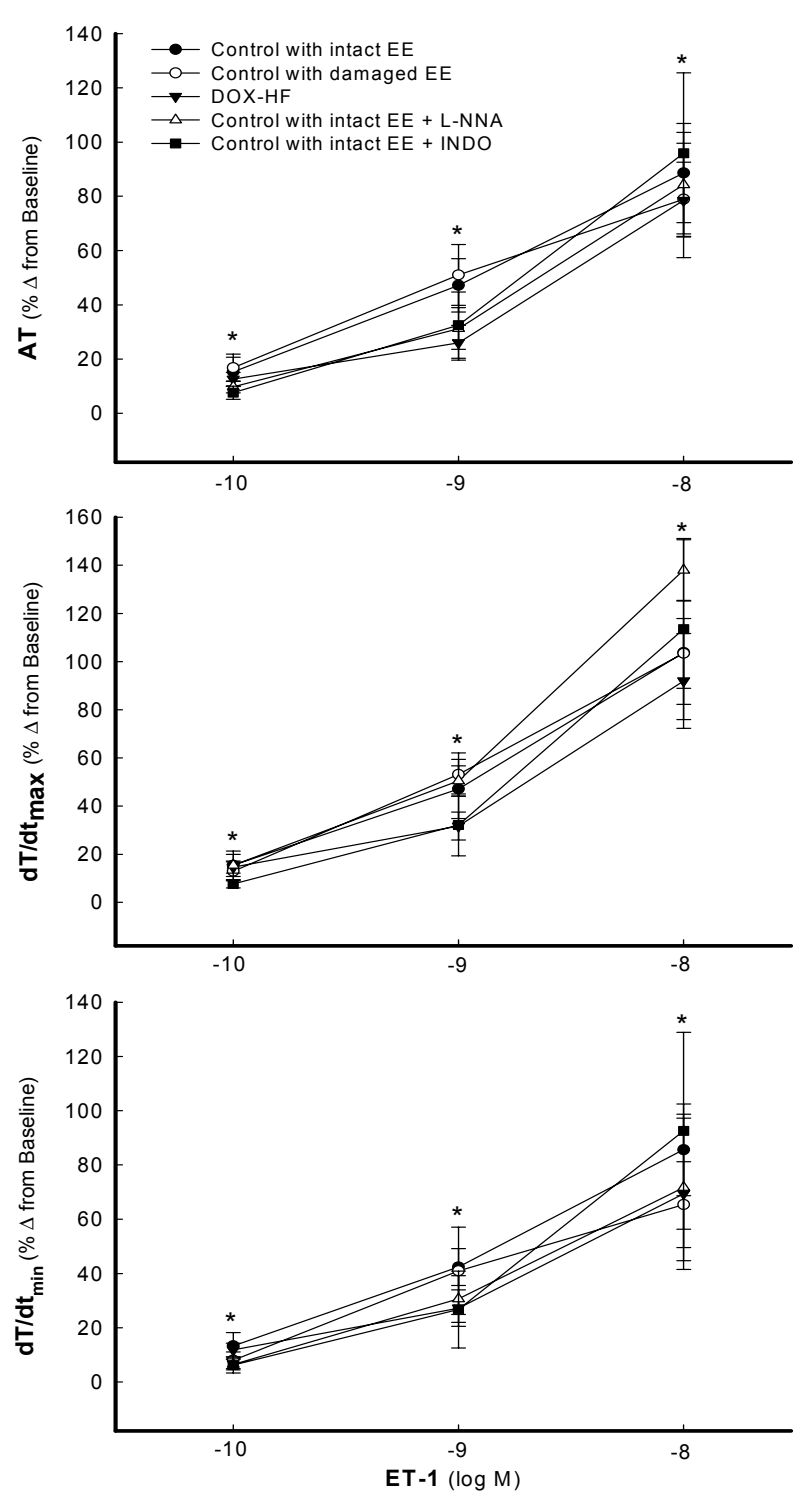

Fig. 2. Concentration-response curves for the effect of ET-1 on the contractile parameters of rabbit papillary muscles in various experimental conditions: Control group with intact endocardial endothelium (EE; full circles, $n=9$ ); Control group with damaged EE (open circles, $n=9$ ); Control group with intact $E E$ and in the presence of $\mathrm{N}^{\mathrm{G}}$-nitro-L-arginine ( $\mathrm{L}$-NNA, open triangles, $\mathrm{n}=8$ ); Control group with intact $\mathrm{EE}$ and in the presence of Indomethacin (INDO, full squares, $n=7$ ) and doxorubicin-induced heart failure group (DOX-HF; full triangles, $\mathrm{n}=8$ ). AT, active tension; $\mathrm{dT} / \mathrm{dt}_{\max }$ maximum velocity of tension rise; $\mathrm{dT} / \mathrm{dt}_{\min }$, maximum velocity of tension decline. Mean \pm S.E.M.; percentage of baseline. $* \mathrm{P}<0.05$ vs, baseline.

monitored echocardiographically to estimate morphological and functional alterations during the development of HF. Hemodynamic studies performed one week after the last administration of DOX also showed the presence of systolic and diastolic dysfunction in DOX-HF animals. In addition, as contractile dysfunction in papillary muscles is most often not evident from changes in baseline performance of muscles that are

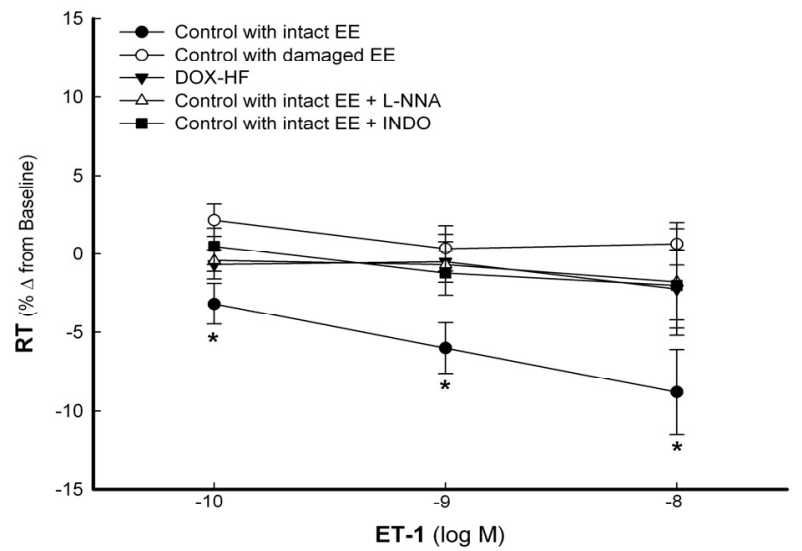

Fig. 3. Concentration-response curves for the effect of ET-1 on resting tension (RT) of rabbit papillary muscles in various experimental conditions: Control group with intact endocardial endothelium ( $E E$; full circles, $n=9$ ); Control group with damaged EE (open circles, $n=9$ ); Control group with intact $E E$ and in the presence of $\mathrm{N}^{G}$-nitro-L-arginine ( $\mathrm{L}-\mathrm{NNA}$, open triangles, $\mathrm{n}=8$ ) Control group with intact EE and in the presence of indomethacin (INDO, full squares, $\mathrm{n}=7$ ) and doxorubicin-induced heart failure group (DOX-HF; full triangles, $\mathrm{n}=8$ ). Mean \pm S.E.M.; percentage of baseline. $* \mathrm{P}<0.05 \mathrm{vs}$. baseline.

contracting at low stimulating frequencies, but rather on an impaired response to increased frequencies (Endoh 2004), contractility-frequency relationships were studied. We found that although baseline performance of normal and DOX-HF muscles was similar, contrary to the former, the latter showed decreased contractility to increased frequencies, indicating contractile dysfunction and a reduced contractile reserve.

Positive inotropic and lusitropic effects of ET-1 have been previously described by several authors in various experimental preparations, although the magnitude of the effects varied among distinct animal species (Endoh et al. 1998). Rabbits belong to the most sensitive animals to ET-1, which was one of the reasons for carrying out the experiments in this species. The magnitude of positive inotropic and lusitropic effects obtained in the present study is in agreement with previously published data on rabbit papillary muscles ( $\mathrm{Li}$ et al. 1991, Leite-Moreira et al. 2003, Leite-Moreira and Bras-Silva 2004, Bras-Silva and Leite-Moreira 2006). These inotropic and lusitropic effects of ET-1 were maintained after damaging EE, blocking $\mathrm{NO}$ and prostaglandins release and in the DOX-HF group. Previous studies in vivo and in vitro showed that the contractile effects of ET-1 were increased (Li and Rouleau 1996), attenuated (Möllmann et al. 2006), maintained (Bras-Silva and Leite-Moreira 2006) or even reversed (Kelso et al. 1996, Thomas et al. 1996, 
MacCarthy et al. 2000) in the presence of HF. This difference could be explained by the different methodological approaches, different animal species and various experimental models of HF.

In the present study, we therefore observed that despite the occurrence of baseline contractile dysfunction in failing hearts, baseline performance of papillary muscles was similar in control and doxorubicin-treated animals. Furthermore, these muscles exhibited the same inotropic and lusitropic response to ET-1, but a distinct inotropic response to increasing stimulation rates, closer to the physiological range. The negative force-frequency relationship is a well-known feature of the failing myocardium that can be at least partially attributed to disturbed calcium homeostasis and energy imbalance (Endoh 2004). On the other hand, the contractile response to ET-1 involves distinct cellular mechanisms, which might explain its similar effects in the normal and failing myocardium. Furthermore, ET-1 has the ability to increase cardiac contractile efficiency by lowering ATPase activity (McClellan et al. 1996) and oxygen consumption (Takeuchi et al. 2001) and was considered essential for the contractile efficiency of the failing myocardium (Sakai et al. 1996).

With regard to the effects of ET-1 on the diastolic properties of the myocardium, we found that the decrease in resting tension (increase in myocardial distensibility) observed after an afterloaded twitch in the presence of ET-1 was not present in the failing myocardium. We also confirmed that damaging the EE also blocked this effect confirming our previous observations (Bras-Silva and Leite-Moreira 2006). In previous studies we have also shown that this effect of ET-1 on myocardial distensibility was mediated by $\mathrm{ET}_{\mathrm{A}}$ receptor stimulation (Leite-Moreira et al. 2003), and dependent on endothelial $\mathrm{ET}_{\mathrm{B} 1}$ receptor activity, even if the direct stimulation of either endothelial $\mathrm{ET}_{\mathrm{B} 1}$ or myocardial $\mathrm{ET}_{\mathrm{B} 2}$ receptors did not elicit any effect on this parameter (Bras-Silva and Leite-Moreira 2006). If we take into account that endocardial endothelium is dysfunctional in the DOX-HF model (Bras-Silva et al. 2006) and that the acute effects of ET-1 on myocardial distensibility are blocked when the EE is damaged, it seems plausible that the blunted effects of ET-1 on myocardial distensibility in the failing myocardium could be explained by EE dysfunction.

Once NO and prostaglandins are two of the most important endothelial mediators and they are known to be released by the endothelium in response to $\mathrm{ET}_{\mathrm{B} 1}$ receptor stimulation (de Nucci et al. 1988, Thiemermann et al. 1989, Filep et al. 1991, Hirata et al. 1993 Leite-Moreira and Bras-Silva 2004), which also influences ET-1 effect on myocardial distensibility (Bras-Silva and LeiteMoreira 2006), we investigated how these two agents modulate the ET-1 effects. We found that similarly to what happened after damaging EE, after blocking of NO or prostaglandin release the ET-1-induced decrease in resting tension (increase in distensibility) was not observed.

NO has been shown to increase diastolic distensibility (Paulus and Shah 1999, Paulus et al. 1994). This effect seems to be mediated by reduction of myofilamentary calcium sensitivity because of phosphorylation of troponin I by cGMP-dependent protein kinase (Shah and MacCarthy 2000). Direct myocardial actions of prostaglandins are still not clear. With regard to inotropy both negative (Schor and Hohlfeld 1992) and positive (Mohan et al. 1995) effects were shown in isolated papillary muscles. Regarding lusitropy prostaglandins were recently shown to preserve early active diastolic relaxation (Kisch-Wedel et al. 2005) and to modulate the premature onset of tension decline promoted by ghrelin (Soares et al. 2006). These two agents, NO and prostaglandins, have also been implicated in the negative inotropic effects resulting from selective $\mathrm{ET}_{\mathrm{B} 1}$ receptor stimulation (Leite-Moreira and Bras-Silva 2004). It seems that independently of the direct actions of each of these endothelial agents, they are able to regulate both systolic and diastolic effects of ET-1.

Concerning the pathophysiological relevance of our findings, we must point out that a lower resting tension of the cardiac muscle indicates the ventricle can reach higher filling volumes at lower filling pressures, which is undoubtedly quite a powerful adaptation mechanism. These acute beneficial ET-1 effects on diastolic function seem to be overcome by its role in progression to cardiac fibrosis and ventricular remodeling when its levels remain chronically elevated (Brunner et al. 2006). Additionally, the results of the present study emphasize that humoral influences on diastolic cardiac function are modulated by the interaction with endocardial endothelial mediators, such as NO and prostaglandins, which being altered in the failing heart might provide new elements for the comprehension of the pathophysiology of HF. Finally, doxorubicin is an antineoplastic antibiotic widely used in the treatment of a variety of cancers, and its clinical use is limited as the result of a severe, dose-dependent cardiotoxicity (Monnet 
and Chachques 2005). In this context, our findings might also be relevant to a better understanding of the pathophysiology of DOX-induced cardiomyopathy, so that efficient protective and/or therapeutic strategies can be developed in patients treated with this chemotherapeutic agent.

\section{Conflict of Interest}

There is no conflict of interest.

\section{Acknowledgements}

Supported by grants from the Portuguese Foundation for Science and Technology (no. POCI/SAUFCT/60803/2004) through Cardiovascular R\&D Unit (FCT no. 51/94). Carmen Brás-Silva was supported by a grant from the Portuguese Foundation for Science and Technology (no. SFRH/ BD/ 10249/ 2002). The results were presented in part at the American Heart Association Scientific Sessions 2006. Chicago, Illinois: November 12-15, 2006.

\section{References}

ARNOLDA L, MCGRATH B, COCKS M, SUMITHRAN E, JOHNSTON C: Adriamycin cardiomyopathy in the rabbit: an animal model of low output cardiac failure with activation of vasoconstrictor mechanisms. Cardiovasc Res 19: 378-382, 1985.

ATTINA T, CAMIDGE R, NEWBY DE, WEBB DJ: Endothelin antagonism in pulmonary hypertension, heart failure, and beyond. Heart 91: 825-831, 2005.

BRÁS-SILVA C, LEITE-MOREIRA AF. Obligatory role of the endocardial endothelium in the increase of myocardial distensibility induced by endothelin-1. Exp Biol Med 231: 876-881, 2006.

BRÁS-SILVA C, FONTES-SOUSA A, MOURA C, AREIAS JC, LEITE-MOREIRA AF: Impaired response to ETB receptor stimulation in heart failure. Functional evidence of endocardial endothelial dysfunction? Exp Biol Med 231: 893-898, 2006.

BRUNNER F, BRÁS-SILVA C, CERDEIRA AS, LEITE-MOREIRA AF: Cardiovascular endothelins: essential regulators of cardiovascular homeostasis. Pharmacol Ther 111: 508-531, 2006.

BRUTSAERT DL: Cardiac endothelial-myocardial signaling: its role in cardiac growth, contractile performance, and rhythmicity. Physiol Rev 83: 59-115, 2003.

BRUTSAERT DL, MEULEMANS AL, SPIDO KR, SYS SU. Effects of damaging endocardial surface on the mechanical performance of isolated cardiac muscle. Circ Res 62: 358-366, 1988.

CORREIA-PINTO J, HENRIQUES-COELHO T, RONCON-ALBUQUERQUE R JR, LEITE-MOREIRA AF: Differential right and left ventricular diastolic tolerance to acute afterload and NCX gene expression in Wistar rats. Physiol Res 55: 513-26, 2006.

DE NUCCI G, THOMAS R, D’ORLEANS-JUSTE P, ANTUNES E, WALDER C, WARNER TD, VANE JR: Pressor effects of circulating endothelin are limited by its removal in the pulmonary circulation and by release of prostacyclin and endothelium-derived relaxation factor. Proc Natl Acad Sci USA 85: 9797-9800, 1988.

ENDOH M: Force-frequency relationship in intact mammalian ventricular myocardium: physiological and pathophysiological relevance. Eur J Pharmacol 500: 73-86, 2004.

ENDOH M, FUJITA S, YANG HT, TALUKDER MA, MARUYA J, NOROTA I: Endothelin: receptor subtypes, signal transduction, regulation of $\mathrm{Ca}^{2+}$ transients and contractility in rabbit ventricular myocardium. Life Sci 62: 1485-1489, 1998.

FILEP JG, BATTISTINI B, COTE YP, BEAUDOIN AR, SIROIS P: Endothelin1 induces prostacyclin release from bovine aortic endothelial cells. Biochem Biophys Res Commun 177: 171-176, 1991.

FIRTH JD, ROBERTS FC, RAINE AEG: Effect of endothelin on the function of isolated perfused working rat heart. Clin Sci (Colch) 79: 221-226, 1990.

FONTES-SOUSA AP, BRÁS-SILVA C, MOURA C, AREIAS JC, LEITE-MOREIRA AF: M-mode and Doppler echocardiographic reference values for New Zealand white male rabbits. Am J Vet Res 67: 1725-1729, 2006.

HIRATA Y, EMORI T, EGUCHI S, KANNO K, IMAI T, OHTA K, MARUMO F: Endothelin receptor subtype B mediates synthesis of nitric oxide by cultured bovine endothelial cells. J Clin Invest 91: 1367-1373, 1993. 
KELSO EJ, GERAGHTY RF, MCDERMOTT BJ, TRIMBLE ER, NICHOLLS DP, SILKE B: Mechanical effects of ET-1 in cardiomyocytes isolated from normal and heart-failed rabbits. Mol Cell Biochem 157: 149-155, 1996.

KISCH-WEDEL H, KEMMING G, MEISNER F, FLONDOR M, BRUHN S, KOEHLER C, MESSMER K, ZWISSLER B: Effect of prostaglandin $\mathrm{I}_{2}$ analogues on left ventricular diastolic function in vivo. Eur $J$ Pharmacol 517: 208-216, 2005.

LEITE-MOREIRA AF, CORREIA-PINTO J: Load as an acute determinant of end-diastolic pressure-volume relation. Am J Physiol 280: H51-H59, 2001.

LEITE-MOREIRA AF, BRÁS-SILVA C: Inotropic effects of $\mathrm{ET}_{\mathrm{B}}$ receptor stimulation and their modulation by endocardial endothelium, NO, and prostaglandins. Am J Physiol 287: H1194-H1199, 2004.

LEITE-MOREIRA AF, CORREIA-PINTO J, GILLEBERT TC: Afterload induced changes in myocardial relaxation: a mechanism for diastolic dysfunction. Cardiovasc Res 43: 344-353, 1999.

LEITE-MOREIRA AF, BRÁS-SILVA C, PEDROSA C, ROCHA-SOUSA A: ET-1 increases distensibility of acutely loaded myocardium: a novel $\mathrm{ET}_{\mathrm{A}}$ and $\mathrm{Na}^{+} / \mathrm{H}^{+}$exchanger-mediated effect. Am J Physiol 284: H1332-H1339, 2003.

LI K, ROULEAU JL: Altered responsiveness to endothelin-1 of myocardium from pacing-induced heart failure model in the dog. Cardiovasc Drugs Ther 10: 107-112, 1996.

LI K, STEWART DJ, ROULEAU JL: Myocardial contractile actions of endothelin-1 in rat and rabbit papillary muscles. Role of endocardial endothelium. Circ Res 69: 301-312, 1991.

MACCARTHY PA, GROCOTT-MASON R, PRENDERGAST BD, SHAH AM: Contrasting inotropic effects of endogenous endothelin in the normal and failing human heart: studies with an intracoronary $\mathrm{ET}_{\mathrm{A}}$ receptor antagonist. Circulation 101: 142-147, 2000.

MCCLELLAN G, WEISBERG A, WINEGRAD S: Effect of endothelin-1 on actomyosin ATPase activity. Implications for the efficiency of contraction. Circ Res 78: 1044-1050, 1996.

MOHAN P, BRUTSAERT DL, SYS SU: Myocardial performance is modulated by interaction of cardiac endothelium derived nitric oxide and prostaglandins. Cardiovasc Res 29: 637-640, 1995.

MÖLLMANN H, SCHMIDT-SCHWEDA S, NEF H, MOLLMANN S, BURSTIN JV, KLOSE S, ELSASSER A, HOLUBARSCH CJ: Contractile effects of angiotensin and endothelin in failing and non-failing human hearts. Int J Cardiol 114: 34-40, 2007.

MONNET E, CHACHQUES JC: Animal models of heart failure: what is new? Ann Thorac Surg 79: 1445-1453, 2005.

PAULUS WJ, SHAH AM: NO and cardiac diastolic function. Cardiovasc Res 43: 595-606, 1999.

PAULUS WJ, VANTRIMPONT PJ, SHAH AM: Acute effects of nitric oxide on left ventricular relaxation and diastolic distensibility in humans. Circulation 89: 2070-2078, 1994.

SAKAI S, MIYAUCHI T, SAKURAI T, KASUYA Y, IHARA M, YAMAGUCHI I, GOTO K, SUGISHITA Y: Endogenous endothelin-1 participates in the maintenance of cardiac function in rats with congestive heart failure. Marked increase in endothelin-1 production in the failing heart. Circulation 93: 1214-1222, 1996.

SCHROR K, HOHLFELD TH: Inotropic actions of eicosanoids. Basic Res Cardiol 87: 2-11, 1992.

SHAH AM, LEWIS MJ, HENDERSON AH: Inotropic effects of endothelin in ferret ventricular myocardium. Eur $J$ Pharmacol 163: 365-367, 1989.

SHAH AM, MACCARTHY PA: Paracrine and autocrine effects of nitric oxide on myocardial function. Pharmacol Ther 86: 49-86, 2000.

SOARES JB, ROCHA-SOUSA A, CASTRO-CHAVES P, HENRIQUES-COELHO T, LEITE-MOREIRA AF: Inotropic and lusitropic effects of ghrelin and their modulation by the endocardial endothelium, NO, prostaglandins, GHS-R1a and $\mathrm{K}_{\mathrm{Ca}}$ channels. Peptides 27: 1616-1623, 2006.

TAKEUCHI Y, KIHARA Y, INAGAKI K, YONEDA T, SASAYAMA S: Endothelin-1 has a unique oxygen-saving effect by increasing contractile efficiency in the isolated rat heart. Circulation 103: 1557-1563, 2001.

THIEMERMANN C, LIDBURY PS, THOMAS GR, VANE JR: Endothelin 1 releases prostacyclin and inhibits ex vivo platelet aggregation in the anesthetized rabbit. J Cardiovasc Pharmacol 13: S138-S141, 1989. 
THOMAS PB, LIU EC, WEBB ML, MUKHERJEE R, HEBBAR L, SPINALE FG: Exogenous effects and endogenous production of endothelin in cardiac myocytes: potential significance in heart failure. Am J Physiol 271: H2629H2637, 1996.

YANAGISAWA M, KURIHARA H, KIMURA S, TOMOBE Y, KOBAYASHI M, MITSUI Y, YAZAKI Y, GOTO K, MASAKI T: A novel potent vasoconstrictor peptide produced by vascular endothelial cells. Nature 332: 411415, 1988. 